\title{
From the ASCO President
}

\section{Supporting Patient Access to High-Quality Cancer Care}

Initiatives that support patient access to high-quality cancer care are among the highest priorities of ASCO. As we approach a new Congress in January, there remain many challenges and opportunities for oncology practice and research. With the arrival of Allen Lichter, MD, as ASCO's Executive Vice President and CEO, and the continued involvement of Joseph Bailes, MD (who adeptly steered ASCO over the past year), we will continue to actively engage to achieve positive outcomes on these key policy and practice issues.

One area of intense concern is the ongoing reform of Medicare payments for cancer care. While the Medicare Modernization Act (MMA) legislation moved the system toward more accurate payments for chemotherapy drugs and services, the appropriate balance in payment for each has not yet been achieved.

ASCO has worked with Representative Ralph Hall (R, Tex) to develop legislation that would allow Medicare to pay higher than the "average sales price" (ASP) when a drug is not widely available at that price. The Hall legislation would make other adjustments to ensure that the Medicare payment accurately reflects the purchasing experience of the practicing oncologist including removing the "prompt pay discount" from the formula for ASP. ASCO is also supporting a bill introduced by Representatives Lois Capps (D, Calif) and Tom Davis (R, Va) that would establish a new Medicare service for comprehensive cancer care planning and coordination at the time of diagnosis, at the end of active treatment, or when there is a change in the cancer survivor's condition or care.

ASCO's Quality Oncology Practice Initiative (QOPI) is an important tool for self-assessment, peer comparison, and quality improvement for the practicing oncologist. QOPI registration opened to ASCO members in January 2006; currently, there are more than 185 practices enrolled across the United States, representing more than 1,000 oncologists. Tools like QOPI will help oncologists embrace self-assessment and facilitate the transition to new pay-for-reporting or pay-for-performance systems being contemplated by Medicare officials and private payers.

ASCO has taken the position that adherence to evidence-based guidelines should be the basis for quality monitoring and payment systems built on quality of care. In addition to QOPI, another program enhancing self-reporting and adherence to guidelines is the 2006 Medicare Demonstration Project, in which medical oncologists are reimbursed for reporting their compliance with practice guidelines. As a Co-Chair of the Cancer Quality Alliance, ASCO has urged Congress and the Administration to continue the Demonstration Project beyond 2006 to ensure collection of sufficient longitudinal data to inform future pay-for-performance decisions.

During the 1990s, coverage of clinical trials was perhaps ASCO's number one policy objective. In 2000, President Clinton issued an Executive Memorandum requiring Medicare to cover routine patient care costs in most clinical trials. The ensuing National Coverage Determination has been a great benefit to practicing oncologists and their patients by reducing substantially the risk of denials of reimbursement in clinical trials, in Medicare as well as private insurance, which often follows Medicare payment policies. This Medicare policy has facilitated participation in clinical research, and faster accruals translate to faster advances in treatment.

In early August of this year, the Medicare program issued a notice of "reconsideration" seeking comments on a variety of issues under the policy. ASCO has submitted aggressive comments in support of maintaining current policy, but with certain refinements to address the few problems that have been identified by practicing oncologists. One such concern is the difficulty that Medicare managed care enrollees experience because they are required to pay the $20 \%$ coinsurance applicable to fee-for-service rather than the typically lower Medicare managed-care coinsurance. ASCO has suggested administrative steps that could be taken to correct this shortcoming, and will continue to monitor Medicare's responses to our concerns.

When a new Congress convenes in 2007, ASCO will be well represented in Washington by volunteers from the relevant ASCO committees, its talented staff, and the new leadership of Allen Lichter.

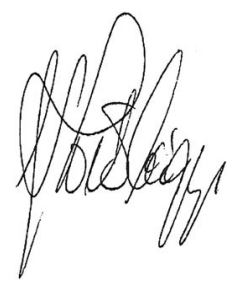

